\section{Drs. Waljee and Chung reply}

To the Editor:

We appreciate the opportunity to respond to the thoughtful comments of Drs. Momohara, Yano, Sakuma, and Ikari ${ }^{1}$ regarding our article examining variation in the rates of surgery for hand and wrist deformities caused by rheumatoid arthritis $(\mathrm{RA})^{2}$. In this study, we examined the determinants of surgical reconstruction among older individuals with RA across the United States using population-based claims data. Overall, rates of surgical reconstruction are low, which is likely attributable to recent advances in the medical management of RA and the introduction of disease-modifying antirheumatic drugs (DMARD). Although rates of surgery did vary by patient factors, a substantial proportion of the variation in rates of surgery was attributable to the regional density of providers, underscoring the influence of clinician practice characteristics and referral patterns on rates of surgery.

Nonetheless, rates have not declined consistently. For example, a recent analysis from the Healthcare Utilization Project data reveals that arthroplasty rates among patients with RA have declined only slightly in comparison to more dramatic declines among patients with other inflammatory conditions ${ }^{3}$. In our analysis, rates of surgery varied widely across geographic regions, and were particularly dependent on the regional density of providers, specifically surgeons and rheumatologists. Although we cannot account for the severity of disease based on administrative claims data, we observed that patients who resided in areas with more rheumatologists were less likely to undergo surgery. It is possible that patients who reside in areas with more rheumatologists may in turn have greater access to optimal medical therapy. It is also possible that regional density relates to referral patterns, and previous research has demonstrated that rheumatologists and surgeons often disagree on the timing, indications, and effectiveness of surgery for RA ${ }^{4}$.

The early initiation of DMARD for patients with RA shortly after diagnosis is considered an essential element of high-quality care among rheumatologists. Moreover, current guidelines advocate a "treat-to-target approach" in which disease activity is regularly assessed, and medical therapy is aggressively titrated to a predefined target disease activity state, either remission or low disease activity ${ }^{5}$. For some conditions, such as peptic ulcer disease, medical therapy has nearly supplanted the need for surgical intervention ${ }^{6}$. As Momohara, et al note, however, antiinflammatory regimens for RA cannot completely eradicate disease activity ${ }^{1}$, and not all patients can tolerate potent immunosuppression. Among the elderly, inflammatory and degenerative arthropathies may overlap, and medical therapy may not alleviate joint destruction entirely. DMARD regimens, particularly biologic DMARD, are expensive, and may be out of reach for many patients despite subsidy plans such as the US Medicare Part D prescription drug coverage ${ }^{7}$. A direct cost-benefit analysis of medical and surgical treatment of RA-related joint deformity remains elusive, but a recent study examining longterm outcomes after silicone metacarpophalangeal arthroplasty demonstrates sustained benefit at a fraction of the cost of immunosuppression regimens ${ }^{8,9}$.

The decision for surgery reflects a complex array of factors arising from patient-provider interactions as well as patient preferences, expectations, and desires regarding pain, joint position, joint appearance, and function, and surgical reconstruction remains an important tool among the treatment resources for patients with RA.

JENNIFER F. WALJEE, MD, MS, Assistant Professor, Department of Surgery, Section of Plastic Surgery, University of Michigan Health System; KEVIN C. CHUNG, MD, MS, Professor of Surgery, Department of Surgery, Section of Plastic Surgery, Assistant Dean for Faculty Affairs, University of Michigan Medical School. Work supported by a 2013 Clinical Arthritis Grant from the American Foundation of Surgery of the Hand.

Address correspondence to Dr. J.F. Waljee, Section of Plastic Surgery, University of Michigan Health System, 2130 Taubman Center, SPC 5340, 1500 E. Medical Center Drive, Ann Arbor, Michigan 48109-5340, USA. E-mail: filip@med.umich.edu

\section{REFERENCES}

1. Momohara S, Yano K, Sakuma Y, Ikari K. Recent orthopedic surgeries aiming to improve quality of life for patients with rheumatoid arthritis. J Rheumatol 2016;43:245-6.

2. Zhong L, Chung KC, Baser O, Fox DA, Yuce H, Waljee JF. Variation in rheumatoid hand and wrist surgery among Medicare beneficiaries: a population-based cohort study. J Rheumatol 2015;42:429-36.

3. Mertelsmann-Voss C, Lyman S, Pan TJ, Goodman SM, Figgie MP, Mandl LA. US trends in rates of arthroplasty for inflammatory arthritis including rheumatoid arthritis, juvenile idiopathic arthritis, and spondyloarthritis. Arthritis Rheumatol 2014;66:1432-9.

4. Alderman AK, Chung KC, Kim HM, Fox DA, Ubel PA. Effectiveness of rheumatoid hand surgery: contrasting perceptions of hand surgeons and rheumatologists. J Hand Surg Am 2003; 28:3-11; discussion 12-13.

5. Wabe N, Sorich MJ, Wechalekar MD, Cleland LG, McWilliams L, Lee A, et al. Characterising deviation from treat-to-target strategies for early rheumatoid arthritis: the first three years. Arthritis Res Ther 2015;17:48.

6. Graham DY. History of Helicobacter pylori, duodenal ulcer, gastric ulcer and gastric cancer. World J Gastroenterol 2014;20:5191-204.

7. Polinski JM, Mohr PE, Johnson L. Impact of Medicare Part D on access to and cost sharing for specialty biologic medications for beneficiaries with rheumatoid arthritis. Arthritis Rheum 2009;61:745-54.

8. Squitieri L, Chung KC, Hutton DW, Burns PB, Kim HM, Mahmoudi E. A 5-year cost-effectiveness analysis of silicone metacarpophalangeal arthroplasty in patients with rheumatoid arthritis. Plast Reconstr Surg 2015;136:305-14.

9. Chung KC, Nellans KW, Burns PB, Wilgis EF, Burke FD, Fox DA, et al. Patient expectations and long-term outcomes in rheumatoid arthritis patients: results from the SARA (Silicone Arthroplasty in Rheumatoid Arthritis) study. Clin Rheumatol 2015;34:641-51.

J Rheumatol 2016;43:1; doi:10.3899/jrheum.150852 